\title{
Effects of blood parasite infection and innate immune genetic diversity on mating patterns in a passerine bird breeding in contrasted habitats
}

\author{
Dany Garant $^{\text {Corresp., }}{ }^{1}$ ，Audrey Bourret ${ }^{1}$, Clarence Schmitt $^{2}$, Audrey Turcotte ${ }^{1}$, Fanie Pelletier ${ }^{1}$, Marc Bélisle \\ 1 Département de Biologie, Université de Sherbrooke, Sherbrooke, Québec, Canada \\ 2 Institut d'Ecologie et des Sciences de l'Environnement de Paris, Sorbonne Universités, UPMC Univ Paris 06, UPEC, Paris 7, CNRS, INRA, IRD, Paris, France \\ Corresponding Author: Dany Garant \\ Email address: Dany.Garant@USherbrooke.ca
}

Genetic diversity at immune genes and levels of parasitism are known to affect patterns of (dis)assortative mating in several species. Heterozygote advantage and/or good genes should shape mate choice originating from pathogen/parasite-driven selection at immune genes. However, the stability of these associations, and whether they vary with environmental conditions, are still rarely documented. In this study, we describe mating patterns in a wild population of tree swallows (Tachycineta bicolor) over 4 years and assess the effects of haemosporidian parasite infection and immune genetic diversity at $\beta$ defensin genes on those patterns within two habitats of contrasting environmental quality, in southern Québec, Canada. We first show that mating patterns were only very weakly related to individual status of infection by haemosporidian parasites. However, we found a difference between habitats in mating patterns related to infection status, which was likely due to a non-random distribution of individuals, as non-infected mating pairs were more frequent in lower quality habitats. Mating patterns also differed depending on $\beta$-defensin heterozygosity at AvBD2, but only for genetic partners outside of the social couple, with heterozygous individuals pairing together. Our study underlines the importance of considering habitat heterogeneity in studies of sexual selection. 
1 Title: Effects of blood parasite infection and innate immune genetic diversity on mating

2 patterns in a passerine bird breeding in contrasted habitats.

3

4 Authors : Dany Garant ${ }^{1}$, Audrey Bourret ${ }^{1}$, Clarence Schmitt $^{2}$, Audrey Turcotte ${ }^{1}$, Fanie Pelletier ${ }^{1}$, 5 Marc Bélisle ${ }^{1}$

6

7 Affiliations :

81 Département de Biologie, Université de Sherbrooke, 2500 Boulevard de l'Université,

9 Sherbrooke, QC J1K 2R1, Canada

10

112 Sorbonne Université, CNRS, IRD, INRA, Institut d'Ecologie et des Sciences de l'Environnement

12 de Paris, iEES-Paris, Paris, 75005, France

13

14

15

16

17

18 Author for editorial correspondence:

19 Dany.Garant@USherbrooke.ca

20 


\section{Abstract}

23 Genetic diversity at immune genes and levels of parasitism are known to affect patterns of 24 (dis)assortative mating in several species. Heterozygote advantage and/or good genes should shape 25 mate choice originating from pathogen/parasite-driven selection at immune genes. However, the 26 stability of these associations, and whether they vary with environmental conditions, are still rarely 27 documented. In this study, we describe mating patterns in a wild population of tree swallows 28 (Tachycineta bicolor) over 4 years and assess the effects of haemosporidian parasite infection and 29 immune genetic diversity at $\beta$-defensin genes on those patterns within two habitats of contrasting 30 environmental quality, in southern Québec, Canada. We first show that mating patterns were only 31 very weakly related to individual status of infection by haemosporidian parasites. However, we

32 found a difference between habitats in mating patterns related to infection status, which was likely 33 due to a non-random distribution of individuals, as non-infected mating pairs were more frequent 34 in lower quality habitats. Mating patterns also differed depending on $\beta$-defensin heterozygosity at 35 AvBD2, but only for genetic partners outside of the social couple, with heterozygous individuals 36 pairing together. Our study underlines the importance of considering habitat heterogeneity in 37 studies of sexual selection. 


\section{Introduction}

Understanding the factors influencing how individuals select their reproductive partners is central in studies of sexual selection and in evolutionary ecology (Andersson 1994; Jennions \& Petrie 1997). This undertaking is however challenging as several factors can affect mating patterns in wild populations. For instance, genetic diversity at immune genes and parasitism are both known to affect patterns of (dis)assortative mating in several species (Hamitlon \& Zuk 1982; Ejsmond et al. 2014). Theoretical and empirical studies have suggested that such effects may stem from an heterozygote advantage and/or from good genes that would shape mate choice originating from pathogen/parasite-driven selection at immune genes (Penn \& Potts 1999; Ejsmond et al. 2014).

Previous studies have shown that genes of the major histocompatibility complex (MHC), which are involved in adaptive immune responses (reviewed Bernatchez \& Landry 2003), can affect mating patterns based on the genetic complementarity or diversity of partners (reviewed in Kamiya et al. 2014). Genes involved in innate immune responses, such as $\beta$-defensin genes (van Dijk et al. 2008), however, have been less investigated in this context despite their importance in providing the first line of defense during an immune challenge, such as an infection by pathogens or parasites (Delves et al. 2006). Previous studies in passerines showed variation at different $\beta$ defensin genes (henceforth AvBD), which suggest that they could be targeted by selection (Hellgren 2015; Schmitt et al. 2017a). In particular, the strongest evidences of selection were found for locus AvBD2 and AvBD7 in both great tits (Parus major) and tree swallows (Tachycineta bicolor) (Hellgren 2015; Schmitt et al. 2017a).

Haemosporidian parasites are ubiquitous and abundant vector-borne blood parasites that cause a malaria-like disease in birds (Valkiūnas 2005). Infections by these parasites often result in negative effects on body condition, breeding success and survival (Knowles et al. 2010; Asghar et 
63 al. 2015). For instance, chronic infection by haemospridian parasites resulted in birds laying fewer 64 eggs and being less successful at rearing healthy offspring than uninfected birds in great reed

65

66 warblers (Acrocephalus arundinaceus) (Asghar et al. 2015). Thus, resistance to infection from these parasites could be a driving selective force affecting mating patterns in wild bird populations. So far, only a few studies have investigated the dependence on environmental conditions of mate choice patterns resulting from genetic diversity or parasitism (Ingleby et al. 2010). This is surprising given the accumulating evidences over recent years that mate choice and sexual selection will often be context-specific and constrained by different ecological factors (see Robinson et al. 2012; reviewed in Miller \& Svensson 2014). For example, a recent modelling study by Kaiser et al. (2017) showed that ecological and social conditions may affect the strength of sexual selection in socially monogamous bird species.

In this study, we describe mating patterns in a wild population of tree swallows over 4 years, in southern Québec, Canada. To do so, we assess whether mating patterns are related to individual status of infection by haemosporidian parasites and if they differ depending on genetic diversity at two immune $\beta$-defensin genes. Importantly, we also evaluate if these factors affect mating patterns differentially depending on habitat quality, as this population breeds under contrasted levels of agricultural intensification. Previous studies on this population showed that birds nesting in low quality habitats, dominated by intensive cultures, have a lower breeding success (Ghilain \& Bélisle 2008; Lessard et al. 2014). Also, tree swallows display a high rate of extra-pair paternity, as about $50 \%$ of nestlings are fathered by an extra-pair male (i.e. not the social male; see Lessard et al. 2014). Furthermore, previous studies have shown that factors affecting the number of within pair young often differ from the factors affecting number of extra-pair young in tree swallows (Lessard et al. 2014) and in other species (reviewed in Westneat \& Stewart 2003). 
86 These observations support the hypothesis that different mate choice patterns occur among social

87 and extra-pair couples. We thus assessed how parasitism and innate immune genetic diversity

88 shape mating patterns for both social and extra-pair couples.

89

91 Material and methods

92 Study system and data collection

93 This study is part of a long-term research project on tree swallows in southern Québec,

94 Canada, which runs since 2004. The study area covers $10,200 \mathrm{~km}^{2}$ and consists of 400 nest boxes

95 distributed equally among 40 farms over a gradient of agricultural intensification (see Ghilain \&

96 Bélisle 2008 for details). Habitat types found in our study system were classified as intensive

97 farmlands (low quality; e.g. reduced forest cover, loss of marginal habitats and wetlands, and

98 increased field size, resulting in homogenized landscapes) or non-intensive farmlands (high

99 quality; opposite characteristics) based on the percentage of cash crops, such as corn, soybean

100 and other cereals, observed within a 5-km radius around each farm (see Ghilain \& Bélisle 2008;

101 Schmitt et al. 2017b). Previous studies in this system reported lower reproductive success in

102 intensive farmlands than in non-intensive areas (Ghilain \& Bélisle 2008; Lessard et al. 2014). All

103 nest boxes are visited every two days during breeding seasons (early May to mid-July). Breeding

104 females and social males are captured and marked at the nest box during incubation and food

105 provisioning, respectively. Blood samples are collected for subsequent DNA analyses. Data were

106 collected in compliance with the Canadian Council on Animal Care, under the approval of the

107 Université de Sherbrooke Animal Ethics Committee (protocols DG 2014-01 and FP2014-01). 
109

110

111

112

113

114

115

116

117

118

119

121

122

123

124

125

126

127

128

129

130

131

\section{Parasite infection screening}

For this study, 906 adult tree swallows (465 females and 441 males; 1260 samples; Table 1) were sampled between 2012 and 2015 and screened for haemosporidian parasite infection, as detailed in Turcotte et al. (2018). Briefly, the detection of avian malaria from bird blood samples was performed with a nested PCR, which consists of two successive PCR amplifications (Hellgren et al. 2004). To determine if the PCR amplification was successful, $5 \mu$ of the second PCR product was migrated on a $2 \%$ agarose gel stained with ethidium bromide and visualized under UV light. The presence of an infection was confirmed by the detection of an amplification at ca. 500-bp (478-bp for Leucocytozoon and 480-bp for Plasmodium and Haemoproteus without primers).

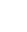

\section{$\beta$-defensin genes analysis}

Of the individuals screened for parasites infection, 69 females and 81 males captured in 2013 and 2014 (on a subsample of 10 farms) were genotyped at $\beta$-defensin loci, as detailed in Schmitt et al. (2017a,c) (see Table 1).

This population of tree swallows has shown variability for several $\beta$-defensin genes for both nonsynonymous and synonymous SNPs (Schmitt et al. 2017a,c). We used only non-synonymous SNPs because the alleles are potentially responsible for functionally different peptides. We choose to perform analyses of mating patterns using heterozygous status at AvBD2 and AvBD7 loci as these were related to different components of immunity in previous research: heterozygosity at AvBD2 was associated with the absence of eggshell bacteria, and homozygosity at AvBD7 with greater innate immune response (Schmitt et al. 2017c). Moreover, among the six available $\beta$-defensin genes in tree swallows, AvBD2 and AvBD7 were the only loci showing some evidence of selection, with lowest Tajima's D scores (Schmitt et al. 2017a). Finally, heterozygosity at both loci 
132 was strongly correlated with total heterozygosity when estimated over all loci considered in

133 previous analyses by Schmitt et al. (2017a; spearman rank correlation with total heterozygosity:

134 AvBD2: rho $=0.61, \mathrm{P}<0.001 ;$ AvBD7: rho $=0.44, \mathrm{P}<0.001)$.

135

136 Mating patterns analysis

137 Mating patterns were defined for both social and extra-pair couples (males assigned using 138 microsatellite loci - see Bourret \& Garant 2017 for details on parentage assignment procedures).

139 In brief, candidate genetic fathers of a given nestling included all males captured on the same farm

140 on both previous and following years and within a 15-km radius of the nestling's nest box (covers

141 males from 1 to 9 farms, mean $=4.8 \pm 1.9$ farms; see Lessard et al. 2014 for a justification of this

142 scale). However, it should be noted that most paternities in our study system are attributed to males

143 located on the same farm as the female ( $85 \%$; see Lessard et al. 2014). Assignment rate was

$14473.8 \%$ for nestlings with DNA samples available (93.5\% of all nestlings). The rate of extra-pair 145 paternities was $52.3 \%$ overall, and did not vary between habitat (low-quality intensive habitats $=$ $14652.3 \%$, non-intensive $\left.=52.4 \%, \chi^{2}=0.0002, \mathrm{df}=1, \mathrm{P}=0.99\right)$.

147 Patterns were described from the female perspective with respect to (1) their social male 148 and (2) the extra-pair males who fathered some or all of their offspring (genetic males). We

149 compared observed mating patterns to random expectations based on i) parasite infection status of 150 each individual and ii) heterozygosity at either AvBD2 or AvBD7 loci. Males were resampled with 151 replacement, within years, and within a buffer of $15 \mathrm{~km}$ for the parasite infection status analysis.

152 Observed numbers were compared to 1000 random expectations for each mating pair status (social 153 and genetic), and P-values were calculated using two-tailed distributions (Fig. S1). We used chi154 square tests to check for differences in status (i.e. infected or not, heterozygous or not) between 
155 social and genetic males, as well as between habitat types (low or high quality). All analyses were

156 conducted in $\mathrm{R}(\mathrm{V}$ 3.3.2, $\mathrm{R}$ core team 2017)

\section{Results}

160

161 (females: $23.7 \%$, males: $16.3 \%$ ). Females that were not infected by haemosporidian parasites

162 showed mating patterns in accord with random expectations (all Ps $>0.17$; Fig 1a). There was a

163 marginally non-significant tendency for infected females to pair with non-infected social males

164 more often than random expectations (social males: $\mathrm{P}=0.094$; genetic males, $\mathrm{P}=0.92$; Fig 1b).

165 No differences in infection status by haemosporidian parasites were observed between social and 166 genetic males for both non-infected $\left(\chi^{2}=0.40, \mathrm{df}=1, \mathrm{P}=0.53\right)$ and infected $\left(\chi^{2}=0.10, \mathrm{df}=1, \mathrm{P}\right.$ $167=0.76)$ females.

168 Heterozygotes at AvBD2 and AvBD7 represented 34.5\% (females: $30.7 \%$, males: 39.5\%) 169 and 11.4\% (females: 12.9\%, males: 9.5\%) of social mating partners, respectively. While 170 homozygous females at AvBD2 showed mating patterns that did not differ from random 171 expectation ( $\mathrm{P}>0.41$; Fig 1c), heterozygote females were more likely to pair with heterozygote 172 genetic males than expected by chance $(\mathrm{P}=0.013)$; a pattern not found for social males $(\mathrm{P}=0.15$; 173 Fig. 1d).

174 The level of heterozygosity at AvBD2 did not differ between social and genetic males, 175 when paired with homozygous females $\left(\chi^{2}=0, \mathrm{df}=1, \mathrm{P}=1.00\right.$; Fig $\left.1 \mathrm{c}\right)$. However, social males 176 showed a lower proportion of heterozygous individuals compared to genetic males, when paired 
177 with heterozygous females $\left(\chi^{2}=6.49, \mathrm{df}=1, \mathrm{P}=0.011\right.$; Fig $\left.1 \mathrm{~d}\right)$. None of the analyses revealed

178 significant differences in mating patterns related to AvBD7 (all Ps > 0.12; Fig S3).

179 Mating patterns related to haemosporidian parasite infection status differed between

180 habitats for both social and genetic males (all Ps $<0.001$; Fig $2 \mathrm{a}, \mathrm{b}$ ). This was likely due to a non-

181 random distribution of individuals with different infection status among habitats, as non-infected

182 mating pairs were more frequent in low quality, more intensive, habitats (Fig. 2a,b). We observed

183 no differences between habitats in mating patterns related to AvBD2 (all Ps $>0.83$; Fig 2c,d) or

184 AvBD7 heterozygosity status (all Ps > 0.30; Fig S3).

185

186

187 Discussion

188 Our results showed a weak effect of infection status by haemosporidian parasites on mating

189 patterns. There was only a marginally non-significant tendency for infected females to pair with

190 non-infected social males more often than expected by chance. In tree swallows, both females and

191 social males provide food to offspring during the nestling phase (McCarty 2002). Previous studies

192 however provided conflicting results concerning the importance of paternal care in this species

193 with some finding no benefits on females' reproductive success (Dunn and Hanson 1992) and

194 other showing positive effects (Whittingham et al. 1994). Our results suggest that the choice of

195 social partners by females, who may themselves be limited in their capacity to raise young due to

196 infection by parasites, may be somewhat directed toward healthier males that will help with

197 offspring care and competition for nesting sites.

198 We also showed assortative mating patterns of genetic pairs based on heterozygosity at one

199 of two $\beta$-defensin loci. Heterozygous females at AvBD2 were more likely to be mated with 
200 heterozygous genetic males at this locus. Several factors could explain this result. For instance,

201 the pattern observed could depend on the female's capacity to assess the genetic diversity of her

202 partners and/or the female's level of choosiness, which could itself be affected by her own

203 heterozygosity (reviewed in Kempenaers 2007). Different signals, such as plumage coloration, are

204 related to male reproductive success in this system (Van Wijk et al. 2016) and could thus be used

205 as indicators of heterozygosity. Another possible explanation for our result is that patterns of

206 assortative mating are also determined by mutual mate choice, where not only females, but also

207 males, would display preferences for heterozygous partners (García-Navas et al. 2009;

208 Kempenaers 2007). Our result is thus partly in line with theory suggesting that heterozygosity

209 should be favoured by mate choice (Brown 1997) and previous evidences that females increase

210 heterozygosity of their offspring via extra-pair matings (Foerster et al. 2003), including in tree

211 swallows (Stapleton et al. 2007). A previous study conducted in this system provided some

212 evidence that heterozygosity at AvBD2 was marginally, negatively associated with the presence

213 of eggshell heterotrophic bacteria present in nests. Additional analyses however revealed no

214 evidence for an effect of genetic diversity at this locus on fledging success of females (Schmitt et

215 al. 2017c). Further research is needed to conclude on the underlying processes modulating the

216 trend we observed.

217 We found some evidence that environmental conditions associated with agricultural

218 practices affected the overall distribution of mating patterns. Mating patterns related to parasite

219 infection status differed between habitats for both social and genetic males, which can be explained

220 by a non-random distribution of individuals, with infected individuals found in greater proportion

221 in non-intensively cultivated habitats. Indeed, additional simulation analyses conducted within

222 each habitat, with smaller sample sizes but allowing to control for differences among habitats in 
223 distribution of individuals, revealed that the differences in mating patterns were not significant at

224 the within-habitat scale (all P-values $>0.05$; see Supplementary material).

225 While mate choice patterns are occurring prior to the sampling for infection, most of the

226 infections detected are probably chronic (Turcotte et al. 2018). Hence, measuring infection status

227 after mate choice has occurred likely gives a good picture of this aspect at the time mating choices

228 were made. It is probable, however, that some of the infections occurred on the breeding grounds,

229 as we previously showed that local transmission is present in this study system (Turcotte et al.

230 2018). This local transmission could also drive to some extent the non-random distribution of

231 infected individuals we reported here. A previous study in this system by Turcotte et al. (2018)

232 showed that non-intensive farmlands were associated with higher Leucocytozoon parasites

233 prevalence. These types of land covers correspond to more heterogeneous agricultural landscapes

234 with lower pesticide use (Ghilain and Bélisle, 2008), which thus tend to support greater vector and

235 host abundances (see Bonneaud et al. 2009 for example). Our results are thus partly in line with

236 previous studies showing that mate choice in birds may depend on environmental contexts

237 (O’Brien \& Dawson 2007; Robinson et al. 2012).

238

239

240 Conclusion

241 We showed that mating patterns were different depending on heterozygosity at an immune

$242 \beta$-defensin locus, but that they only weakly differed according to infection status by

243 haemosporidian parasites. Furthermore, mating patterns related to parasites infection status were

244 different between habitats of contrasted qualities, indicating a possible effect of the environment

245 in driving sexual selection mechanisms. Given that human-driven habitat changes fundamentally 
246 modify ecosystems across the globe and can modulate wildlife mating patterns, integrating them

247 into sexual selection studies will provide critical insights on their potential consequences on wild 248 populations. 


\section{Data accessibility}

251 The raw data have been uploaded as Supplementary files

252

\section{Acknowledgements}

254 We thank two anonymous reviewers for helpful comments on a previous version of the manuscript.

255 We thank all graduate students and field and laboratory assistants who have contributed to the 256 collection of data and laboratory analysis. We also thank the 40 farmers who provide access to 257 their land each year.

258 


\section{References}

261 Andersson M. 1994. Sexual selection. Princeton University Press; Princeton, NJ.

262 Asghar M, Hasselquist D, Hansson B, Zehtindjiev P, Westerdahl H, Bensch S. 2015. Hidden costs

263 of infection: chronic malaria accelerates telomere degradation and senescence in wild birds.

$264 \quad$ Science $347,436-438$.

265 Bernatchez L, Landry C. 2003. MHC studies in nonmodel vertebrates: what have we learned about natural selection in 15 years? J. Evol. Biol. 16, 363-377.

267 Bonneaud C, Sepil I, Milá B, Buermann W, Pollinger J, Sehgal RNM, Valkiūnas G, Iezhova TA,

268 Saatchi S, Smith TB 2009. The prevalence of avian Plasmodium is higher in undisturbed

269 tropical forests of Cameroon. J. Trop. Ecol. 25, 439-447.

270 Bourret A, Garant D. 2017. An assessment of the reliability of quantitative genetics estimates in

271 study systems with high rate of extra-pair reproduction and low recruitment. Heredity. 118,

272 229-238.

273 Brown JL .1997. A theory of mate choice based on heterozygosity. Behav. Ecol. 8, 60-65.

274 Delves P, Martin S, Burton D, Roitt I. 2006. Roitt's Essential Immunology. John Wiley \& Sons. 275 Wiley-Blackwell, Oxford, UK.

276 Dunn PO, Hannon SJ. 1992. Effects of food abundance and male parental care on reproductive 277 success and monogamy in tree swallows. Auk. 109, 488-499.

278 Ejsmond MJ, Radwan J, Wilson AB. 2014. Sexual selection and the evolutionary dynamics of the 279 major histocompatibility complex. Proc. R. Soc. B. 281, 20141662.

280 Foerster K, Delhey K, Johnsen A, Lifjeld JT, Kempenaers B. 2003. Females increase offspring 281 heterozygosity and fitness through extra-pair matings. Nature. 425, 714-717. 
282 García-Navas V, Ortego J, Sanz JJ. 2009. Heterozygosity-based assortative mating in blue tits 283 (Cyanistes caeruleus): implications for the evolution of mate choice. Proc. R. Soc. B. 276, $284 \quad 2931-2940$.

285 Ghilain A, Bélisle M. 2008. Breeding success of tree swallows along a gradient of agricultural 286 intensification. Ecol. Appl. 18, 1140-1154.

287 Hamilton WD, Zuk M. 1982. Heritable true fitness and bright birds: a role for parasites? Science. $288 \quad 218,384-387$.

289 Hellgren O. 2015. Allelic variation at innate immune genes (avian $\beta$-defensins), within a natural 290 population of great tits. J. Avian Biol. 46, 113-118.

291 Hellgren O, Waldenström J, Bensch S. 2004. A new PCR assay for simultaneous studies of 292 Leucocytozoon, Plasmodium, and Haemoproteus from avian blood. J. Parasitol. 90, 797-802. 293 Ingleby FC, Hunt J, Hosken DJ. 2010. The role of genotype-by-environment interactions in sexual 294 selection. J. Evol. Biol. 23, 2031-2045.

295 Jennions MD, Petrie M 1997. Variation in mate choice and mating preferences: a review of causes 296 and consequences. Biol. Rev. 72, 283-327.

297 Kaiser SA, Risk BB, Sillett TS, Webster MS. 2017. Ecological and social factors constrain spatial 298 and temporal opportunities for mating in a migratory songbird. Am. Nat. 189, 283-296.

299 Kamiya T, O'Dwyer K, Westerdahl H, Senior A, Nakagawa, S. 2014. A quantitative review of 300 MHC-based mating preference: the role of diversity and dissimilarity. Mol. Ecol. 23, 515130155163.

302 Kempenaers B. 2007. Mate choice and genetic quality: a review of the heterozygosity theory. Adv. $303 \quad$ Study Behav. 37, 189-278. 
304 Knowles SCL, Palinauskas V, Sheldon, BC. 2010. Chronic malaria infections increase family

305 inequalities and reduce parental fitness: experimental evidence from a wild bird population.

$306 \quad$ J. Evol. Biol. 23, 557-569.

307 Lessard A, Bourret A, Bélisle M, Pelletier F, Garant D. 2014. Individual and environmental

308 determinants of reproductive success in male tree swallow (Tachycineta bicolor). Behav.

$309 \quad$ Ecol. Sociobiol. 68, 733-742.

310 McCarty JP. 2002. The number of visits to the nest by parents is an accurate measure of food

311 delivered to nestlings in tree swallows. J. Field Ornitho. 73, 9-14.

312 Miller CW, Svensson EI. 2014. Sexual selection in complex environments. Ann. Rev. Entomol. $31359,427-445$.

314 O'Brien EL, Dawson RD. 2007. Context-dependent genetic benefits of extra-pair mate choice in 315 a socially monogamous passerine. Behav. Ecol. Sociobiol. 61, 775-782.

316 Penn DJ, Potts WK. 1999. The evolution of mating preferences and major histocompatibility 317 complex genes. Am. Nat. 153, 145-164.

318 R Core Team. 2017. R: A Language and Environment for Statistical Computing. https://www.R319 project.org/.

320 Robinson MR, Sander van Doorn G, Gustafsson L, Qvarnström A. 2012. Environment-dependent 321 selection on mate choice in a natural population of birds. Ecol. Lett. 15, 611-618.

322 Schmitt C, Garant D, Doyon K, Bousquet N, Gaudreau L, Bélisle M, Pelletier F. 2017a. Patterns 323 of diversity and spatial variability of $\beta$-defensin innate immune genes in a declining wild 324 population of tree swallows. J. Hered. 108, 262-269. 
325 Schmitt C, Garant D, Bélisle M, Pelletier F. 2017b. Agricultural intensification is linked to

326 constitutive innate immune function in a wild bird population. Physiol. Biochem. Zool. 90, $327 \quad 201-209$.

328 Schmitt C, Garant D, Bélisle M, Pelletier F. 2017c. Linking innate immunogenetic variation with 329 phenotypic traits in a wild population of tree swallows, Tachycineta bicolor. Biol. J. Linn. $330 \quad$ Soc. $121,685-697$.

331 Stapleton MK, Kleven O, Lifjeld JT, Robertson RJ. 2007. Female tree swallows (Tachycineta 332 bicolor) increase offspring heterozygosity through extrapair mating. Behav. Ecol. Sociobiol. $333 \quad 61,1725-1733$.

334 Turcotte A, Bélisle M, Pelletier F, Garant D. 2018. Environmental determinants of haemosporidian 335 parasite prevalence in a declining population of Tree Swallows. Parasitology. 145, 961-970.

336 Valkiūnas G. 2005. Avian malaria parasites and other haemosporidia. CRC Press, Boca Raton, 337 USA.

338 van Dijk A, Veldhuizen EJ, Haagsman HP. 2008. Avian defensins. Veter. immunol. 339 immunopathol. 124, 1-18.

340 Van Wijk S, Bourret A, Bélisle M, Garant D, Pelletier F. 2016. The influence of iridescent 341 coloration directionality on male tree swallows' reproductive success at different breeding 342 densities. Behav. Ecol. Sociobiol. 70, 1557-1569.

343 Westneat DF, Stewart IR. 2003. Extra-pair paternity in birds: causes, correlates, and conflict. Ann. 344 Rev. Ecol. Evol. Syst. 34, 365-396.

345 Whittingham LA, Dunn PO, Robertson RJ. 1994. Female response to reduced male parental care 346 in birds: an experiment in tree swallows. Ethology. 96, 260-269. 


\section{Table $\mathbf{1}$ (on next page)}

Sample sizes for adult Tree swallows (total number of individuals sampled per year) included in analyses and known infection status by haemosporidian parasites or genetic diversity at two $\beta$-defensin genes.

Total: total number of individuals (including multiple records of individuals across years). 
1

$\begin{array}{lllll}2012 & 2013 & 2014 & 2015 & \text { Total }\end{array}$

Parasite infection

$\begin{array}{llllll}\text { Females } & 132 & 132 & 177 & 173 & 614\end{array}$

$\begin{array}{llllll}\text { Males } & 138 & 144 & 187 & 177 & 646\end{array}$

AvBD2

$\begin{array}{llll}\text { Females } & 26 & 46 & 72\end{array}$

$\begin{array}{llll}\text { Males } & 33 & 63 & 96\end{array}$

AvBD7

$\begin{array}{llll}\text { Females } & 31 & 49 & 80\end{array}$

$\begin{array}{llll}\text { Males } & 37 & 65 & 102\end{array}$

2

3 


\section{Figure 1 (on next page)}

Difference in proportions of observed and expected mating pairs.

a) Females non-infected by haemosporidian parasites, b) infected females, c) homozygous females at AvBD2 locus and d) heterozygous females at AvBD2, paired with either social (S) or genetic males $(G)$. White bars represent non-infected $(a, b)$ or homozygote $(c, d)$ males, and grey bars, infected $(a, b)$ or heterozygote $(c, d)$ males. P-values $(* P<0.1$; ** $P<0.05)$ are shown. Significance threshold $(P<0.05)$ in each case is represented by a dashed line. 
$\stackrel{\infty}{=} \quad$ apeepy-infected females

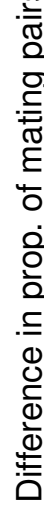

0.04

0.00

ة

$\subseteq 0.02$

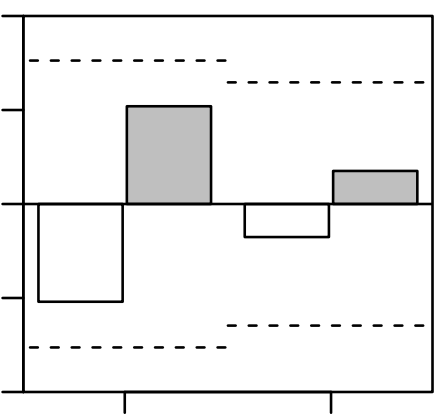

S

G

.

$\cong \quad$ c) Homozygous females

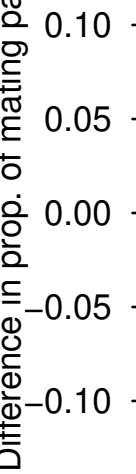

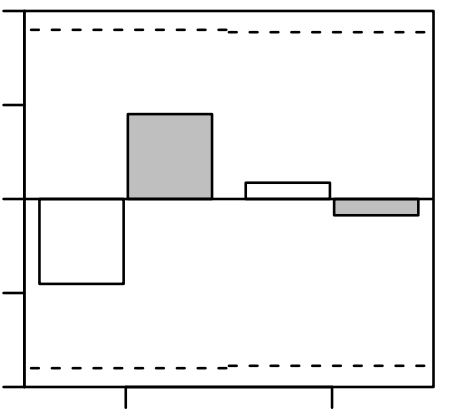

S

G $\stackrel{\infty}{\overline{\bar{*}}}$ Manuscript b) Infected females

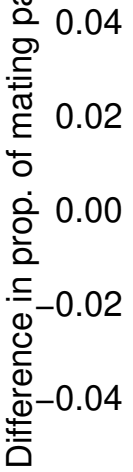

$\cdot \frac{\sqrt{\overparen{N}}}{2}$

d) Heterozygous females

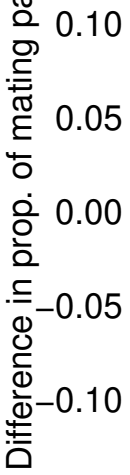

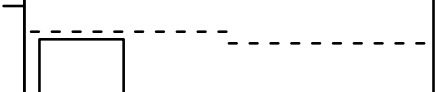
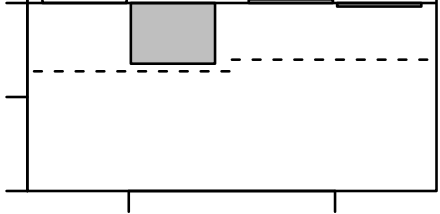

S

G
* 


\section{Figure 2 (on next page)}

Proportions of observed mating pairs between habitats.

White bars: intensive; grey bars: non-intensive as function of infection status by haemosporidian parasites ( $a, b$; non-infected: 0 , infected: 1 ) or heterozygosity at AvBD2 locus (c, d; homozygote: 0 , heterozygote: 1 ), for social couples $(a, c)$ and genetic couples (b, d). P-values (*** $\mathrm{P}<0.001)$ are also shown. 
PeerJ

a) Infection - Social couples

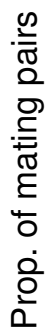

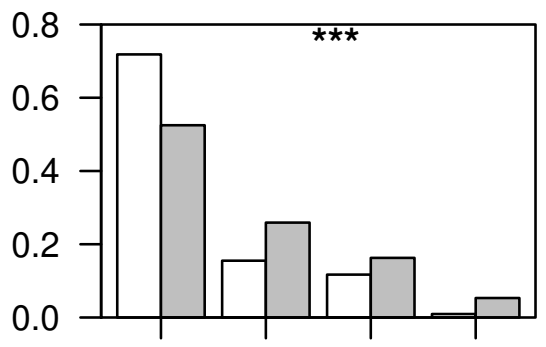

0-0 0-1 1-0 1-1

female-male status

c) Heterozygosity - Social couples

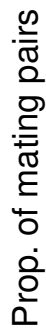

\section{Manuscript to be reviewed}

b) Infection - Genetic couples

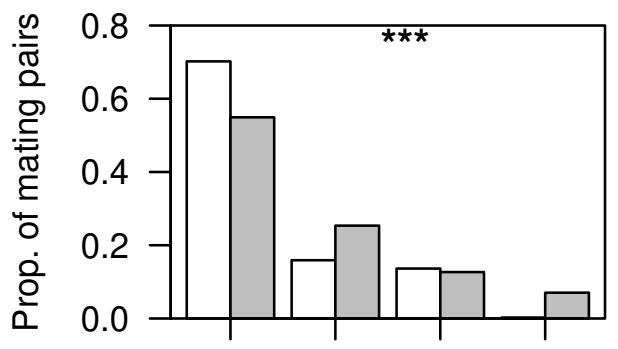

0-0 $\quad 0-1 \quad 1-0 \quad 1-1$

female-male status

d) Heterozygosity - Genetic couples

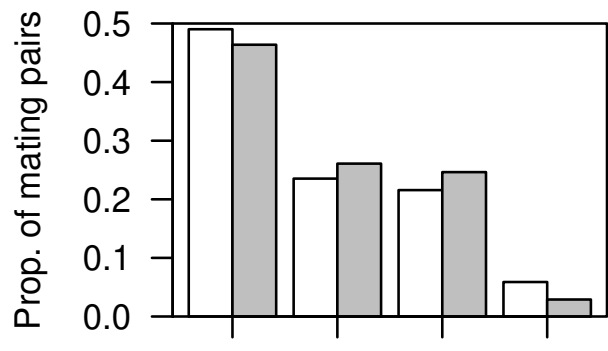

0-0 0-1 1-0 1-1

female-male status 